\title{
Urogenital schistosomiasis and associated determinant factors among senior high school students in the Dutsin-Ma and Safana Local Government Areas of Katsina State, Nigeria
}

\author{
Tolulope Ebenezer Atalabi ${ }^{*}$, Umar Lawal ${ }^{1}$ and Francis Omowonuola Akinluyi ${ }^{2}$
}

\begin{abstract}
Background: Human schistosomiasis is a chronic parasitic disease of poverty caused by the cercariae of digenetic trematodes of the genus Schistosoma. The disease is a major source of morbidity and mortality in 77 low- and middle-income countries in the tropics where 700 million people are at risk. In a bid to provide relevant epidemiological information to boost control of urogenital schistosomiasis at the state level in Nigeria, we conducted this study with the aim of investigating the disease's prevalence and intensity, and the determinant factors responsible for its endemicity.

Methods: Data on risk factors were obtained from a total of 645 students aged $12-25$ years using well- designed questionnaires. Samples were collected between 09:45 and 14:00 in universal bottles. Each10ul centrifuged sample was examined for the eggs of S. haematobium using Motic ${ }^{\circledast}$ (Binocular) Light Microscope (model S-10-P) with a x10 objective. Average infection intensity was recorded as number of eggs per $10 \mathrm{ml}$ of urine sample. Survey data were entered into Microsoft Excel 2010 and analyzed using Epi Info ${ }^{\mathrm{TM}}$ 7. Associations among variables were determined using the chi square test and bivariate and multivariate logistic regressions.

Results: Prevalence of urogenital schistosomiasis was $30.54 \%$ among the study population, with a mean infection intensity of $30.27 \mathrm{eggs} / 10 \mathrm{ml}$ of urine. Prevalence and average intensity were higher in males $(28.37 \%$ and 32.21 eggs $/ 10 \mathrm{ml}$ of urine respectively) than in females $(2.17 \%$ and 5 eggs $/ 10 \mathrm{ml}$ of urine respectively). Water contact activities $\left(X^{2}=29.031, P=0.0000\right.$ ), sex (male) $\left[X^{2}=109.82 ; P<0.0001\right]$, location (Dutsin-Ma) $\left[X^{2}=7.19 ; P=0.0073\right]$, age group 18-20 $\left(X^{2}=4.819, P=0.0281\right)$, altitude $(531-560 \mathrm{~m})\left[X^{2}=6.84, P=0.0089\right]$, fathers doing other brown-collar jobs $\left(X^{2}=8.449\right.$, $P=0.0037)$ and mothers' occupation $\left(X^{2}=9.470, P=0.0021\right)$ were found to be significantly associated with urogenital schistosomiasis. Boys were six times more likely to be infected with the cercariae of $S$. haematobium compared to girls [AOR (95\% C): 6.34 (4.89-8.22)].

Conclusions: Dutsin-Ma and Safana were classified as moderate-risk Local Government Areas for urogenital schistosomiasis. The strong association between the disease and mother's occupation is of utmost importance and suggests a promising control measure: that is, directing health education as well as grassroots mass chemotherapeutic intervention with praziquantel at mothers. A good network including treated pipe-borne water, drainage system, and sewage disposal facilities available should be improved upon. Molluscicides should be provided at highly subsidized rate to help control the disease.
\end{abstract}

Keywords: Prevalence, Intensity, Urogenital schistosomiasis, Risk—factors, Katsina State, Nigeria

\footnotetext{
* Correspondence: ebenezer2k2@gmail.com

'Department of Biological Sciences, Faculty of Science, Federal University,

Dutsin-Ma, P.M.B. 5001, Dutsin-Ma, Katsina State, Nigeria

Full list of author information is available at the end of the article
} 


\section{Multilingual abstracts}

Please see Additional file 1 for translations of the abstract into the six official working languages of the United Nations.

\section{Background}

Human schistosomiasis is a chronic parasitic disease of poverty caused by the cercariae of digenetic trematodes of the genus Schistosoma. Also referred to as snail fever, the disease came into the limelight of public health research in 1851, when it was discovered by the German surgeon; Theodor Bilharz in Egypt [1]. Being a major source of morbidity and mortality in 77 low- and middle-income countries in Africa, Asia, the Caribbean, Middle East, and South America, where 700 million people are at risk, the disease is now the second most devastating and dreaded tropical disease in the world after malaria [2-4]. From a total of 207 million global cases, 120 million are reportedly symptomatic and 20 million are severe [2].

In Africa, about 176 million people from 46 countries are reportedly infected with the disease while an alarming 280000 have been estimated to die annually [5].

Nigeria has been described as the most endemic country for schistosomiasis in Sub-Saharan Africa, with 29 million people reportedly infected and an estimated 101.3 million people at risk of infection [6].

An increase in the population density in locations where access to potable water is limited creates a need for alternative water sources, which can be unwholesome. Consequently, communities situated near infested lakes, rivers, ponds and streams, risk getting a severe infection. Studies have shown that the distribution of infection among endemic communities is lopsided with 5-10\% often being heavily infected [7]. Age, sex, altitude and mean annual rainfall have been identified as important risk factors for the transmission of the disease [8, 9]. Domestic chores, irrigation, and recreational activities, coupled with adventure-driven behaviors, mean that school-aged children frequently come into contact with infested water bodies, thereby; making them more at risk of contracting the disease [10]. To corroborate this, a report has shown that $45.93 \%$ of the global population requiring chemotherapeutic interventions with praziquantel is school-aged children [4].

In a bid to provide relevant epidemiological information to boost control of urogenital schistosomiasis at the state level in Nigeria, we conducted this study with the aim of investigating the disease's prevalence and intensity, and the determinant factors responsible for its endemicity.

\section{Methods}

\section{Study area}

The survey was carried out in the Dutsin-Ma and Safana Local Government Areas (LGAs) of Katsina State, North
West Nigeria. The study area covers a total surface area of $809 \mathrm{~km}^{2}$ and is inhabited by 353450 people, according to the 2006 National Census [11]. In Dutsin-Ma, the duration of rainfall is May to September with annual mean of $700 \mathrm{~mm}$. It has a temperature range of $29-31{ }^{\circ} \mathrm{C}$ [12]. Meanwhile, Safana, a neighboring LGA to Dutsin-Ma, has a similar duration of rainfall.

The ethnic groups comprise the Hausa and Fulani, who are predominantly farmers and traders. The study area has a short grass type of savanna and is located at the extreme North of Nigeria.

\section{Study design}

The cross-sectional survey was carried out between May and August, 2015. It was designed to target a total number of 645 senior high school students from the Dutsin-Ma and Safana LGAs.

\section{Inclusion and exclusion criteria}

Students in the age group of $12-25$ years voluntarily enrolled in the study. However, respondents who demonstrated unwillingness were not included in the study.

\section{Sample size and sampling technique}

Six schools were drawn from a list of 20 senior high schools in both LGAs. Sample size was allotted to each school, and by extension, each class of participating students. Six hundred and forty-five students were selected using a simple random sampling technique from a total of 3537 students. The schools selected for the study were: the Government Pilot Senior Secondary School, Safana; the Government Senior Secondary School, Tsaskiyya; the Community Day Senior Secondary School, Safana; the Government Pilot Senior Secondary School, Dutsin-Ma; the Community Day Senior Secondary School, Dutsin-Ma; and the Government Senior Secondary School, Dutsin-Ma.

\section{Data collection \\ Socio-demographic and risk factors}

Well-designed questionnaires were used to collect data on socio-demographic and determinant factors. A schoolbased questionnaire was administered to each principal and was used to collect data on students' population, history of praziquantel distribution, reports of haematuria, and local languages for haematuria (blood in urine) and Bulinus species. Individual questionnaires were used to collect information peculiar to each respondent, while a urinalysis form was used to document urine parameters.

\section{Urine sample collection}

Clean $20 \mathrm{ml}$ plastic health diagnostics universal bottles with screw-caps were used to collect different quantities of terminal urine samples between the hours of 9:45 and 
14:00 [13]. This coincides with the periodicity of egg excretion in S. haematobium-infected respondents [14].

\section{Centrifugation of urine samples}

Test-tubes each containing about $5 \mathrm{ml}$ of urine was loaded into a C2 series Centurion Scientific centrifuge (United Kingdom). Spinning was performed at 2250 revolutions per minute for 1.5 minutes. The supernatant fluid was decanted off, while the egg-containing sediment was dissolved with a small portion of the supernatant fluid to enhance clarity when viewing the wet mount under the microscope.

\section{Microscopic examination of urine for S. haematobium eggs} Each $10 \mu \mathrm{l}$ sample was pipetted onto a grease-free glass slide using an adjustable micro-pipette $(10 \mu \mathrm{l}-100 \mu \mathrm{l})$ and covered at an angle with a glass slip to avoid bubble formation. Examination of samples for S. haematobium eggs was carried out using Motic ${ }^{\bullet}$ Binocular Light Microscope (Chna), model S-10-P, with a x10 objective. For positive samples the eggs were counted and each average count was recorded as number of eggs per $10 \mathrm{ml}$ of urine [15]. Intensity of infection was categorized as light $(<50$ eggs/ $10 \mathrm{ml}$ of urine) or heavy ( $\geq 50$ eggs/10 $\mathrm{ml}$ of urine) [16].

\section{Quality control}

Universal sample bottles had corresponding serial numbers. Urinalysis of each sample was carried out within 90 seconds of inserting dipstick. Depending on whether infection intensity was heavy or light, the number of $S$. haematobium eggs in each sample was counted between two and seven times with the average intensity recorded.

\section{Statistical analysis}

Survey data were entered into Microsoft Excel 2010 (USA) and analyzed using Epi Info ${ }^{\text {Tx }} 7$ (Atlanta, USA). Associations between variables were determined using the chi square test, bivariate and multivariate logistic regressions. Strength of associations was measured using odds ratio (OR) at $95 \%$ confidence intervals (CIs). Crude OR was adjusted using haematuria, a morbidity marker. A $P-$ value of less than 0.05 was considered to be statistically significant.

\section{Ethical approval}

Written ethical permission to conduct the study was given by the Ethical Committee of the Katsina State PostPrimary Education Zonal Office, Dutsin-Ma. School heads and students were briefed about the aims of the study. They orally consented to participate in the study. Information from the respondents was kept confidential. The results of the study were communicated to the school heads, and mass drug administration, in consultation with the state Ministry of Education, was recommended.

\section{Results}

Socio-demographic characteristics of the respondents Of the total 645 students enrolled in the study, 405 $(62.79 \%)$ were males and $240(37.21 \%)$ were females. The mean age (standard deviation, SD) of the respondents was 16.79 (1.97) years. The percentage of students in each age group was as follows: 12-14 (7.91 \%), 15-17 (59.69\%), 18-20 (28.37\%), 21-23 (3.72\%) and $24-26(0.31 \%)$. White-collar (42.48 \%) and browncollar (56.12 \%) jobs were the major occupation categories of the respondents' fathers, while the mothers' occupations were mostly white-collar and brown-collar jobs and housewives, representing $10.23 \%, 52.56 \%$ and $36.90 \%$ of the respondents respectively (see Table 1 ).

\section{Risk factors associated with urogenital schistosomiasis}

Of the 645 students surveyed, 228 (35.35\%) said they had previously swum in water sources, while 303 (46.98\%) previously played in shallow water. Bore-hole, dams, ponds, rivers, streams, wells, taps and sachets were indicated as sources of water for domestic use by 448 (33.81\%), 227 (17.13\%), 43 (3.25\%), 38 (2.87\%), 184 (13.89\%), 148 (11.17\%), 231 (17.43\%), and six (0.45\%) respondents respectively (see Table 2).

Table 1 Socio-demographic features of respondents from Safana and Dutsin-Ma LGAs

\begin{tabular}{|c|c|c|}
\hline Variables & Frequency & Percentage (\%) \\
\hline \multicolumn{3}{|l|}{ Age } \\
\hline $12-14$ & 51 & 7.91 \\
\hline $15-17$ & 385 & 59.69 \\
\hline $18-20$ & 183 & 28.36 \\
\hline $21-23$ & 24 & 3.73 \\
\hline $24-26$ & 2 & 0.31 \\
\hline \multicolumn{3}{|l|}{ Sex } \\
\hline Male & 405 & 62.79 \\
\hline Female & 240 & 37.21 \\
\hline \multicolumn{3}{|l|}{ Father's occupation } \\
\hline White collar job & 274 & 42.48 \\
\hline Farming & 113 & 17.52 \\
\hline Other brown collar jobs & 249 & 38.60 \\
\hline Late & 6 & 0.93 \\
\hline Retiree & 3 & 0.47 \\
\hline \multicolumn{3}{|l|}{ Mother's occupation } \\
\hline White collar job & 66 & 10.23 \\
\hline Farming & 1 & 0.16 \\
\hline Other brown collar jobs & 338 & 52.40 \\
\hline Late & 2 & 0.31 \\
\hline House wifery & 238 & 36.90 \\
\hline Total & 645 & $100 \%$ \\
\hline
\end{tabular}


Table 2 Frequency of risk factors associated with Urogenital schistosomiasis from Safana and Dutsin-Ma LGAs

\begin{tabular}{lll}
\hline Variables & Frequency & Percentage (\%) \\
\hline Swimming experience & 228 & 35.35 \\
Yes & $\frac{417}{645}$ & 64.65 \\
No & $\frac{1}{203}$ & \\
Playing in shallow water & 303 \\
Yes & $\frac{342}{645}$ & 46.98 \\
No & $\underline{4}$ & 53.02 \\
& \\
Sources of water for drinking, & \\
Cooking, washing \& bathing. & \\
Bore hole & 448 & \\
Dam & 227 & 33.81 \\
Pond & 43 & 17.13 \\
River & 38 & 3.25 \\
Stream & 184 & 2.87 \\
Well & 148 & 13.89 \\
Tap & 231 & 11.17 \\
Sachet & 6 & 17.43 \\
Total & 1325 & 0.45 \\
\hline
\end{tabular}

NOTE: Respondents combined multiple water sources for domestic use This informed the higher total number above compared to the 645 interviewed

Prevalence and intensity of urogenital schistosomiasis by study location

The highest prevalence of urogenital schistosomiasis (48.63 \%) was recorded in Darawa in the Dutsin-Ma LGA, with the second highest prevalence (46.15\%) recorded in Tsaskiyya, Safana LGA. The lowest prevalence rate $(18.95 \%)$ was recorded in a Local Government Education Authority location in Safana (see Fig. 1).

Meanwhile, the average infection intensities by location was a bit different in pattern with the highest infection intensity (66.72 eggs/10 $\mathrm{ml}$ of urine), and the second highest infection intensity (56.22 eggs/10 ml of urine) recorded in the Kofa and Sokoto Rima communities respectively in Dutsin-Ma LGA. The lowest infection intensity (3.33 eggs/ $10 \mathrm{ml}$ of urine) was recorded in the Kofa Fada community in Safana LGA (see Fig. 2).

Prevalence and intensity of urogenital schistosomiasis in relation to age and sex

In this survey, the prevalence of urogenital schistosomiasis was $30.54 \%$ with a mean (SD) intensity of 30.27 (50.03) eggs $/ 10 \mathrm{ml}$ of urine. Of the 645 urine samples examined, 197 (30.54 \%) tested positive for S. haematobium eggs, with a total raw egg count of 5,933 (see Table 3).
The prevalence and mean egg count (intensity) was higher in males [28.37 \% (Chi square test $=109.82$, $P<0.0001$ ) and 32.21 eggs $/ 10 \mathrm{ml}$ of urine)] than in females ( $2.17 \%$ and 5 eggs $/ 10 \mathrm{ml}$ of urine). The highest prevalence (16.43\%) was recorded among children in the age group of $15-17$ years (Chi square test $=0.7505, P=0.687$ ) compared to the $12-14,18-20,21-23$ and $24-26$ age groups with prevalence rates of $2.48 \%, 10.38 \%, 1.09 \%$, and $0.16 \%$ respectively. However, as shown in Fig. 3 and Table 3, the highest mean infection intensity (47.5 eggs/ $10 \mathrm{ml}$ of urine) was recorded among the age group of $12-14$ years (Chi square test $=22.3149, P=0.324$ ) compared to $15-17,18-20,21-23$, and $24-26$ age groups with mean infection intensities of $33.77,23.31,8.86$, and 3 eggs/10 $\mathrm{ml}$ of urine, respectively.

\section{Prevalence and intensity of urogenital schistosomiasis in relation to water sources}

The highest infection rate (75\%) was recorded among children who used all the open, potentially infested water sources, for domestic purposes, followed by a rate of $55.56 \%$ recorded among subjects who played in shallow water and swam in the water sources. Meanwhile, the lowest prevalence $(30.31 \%)$ was recorded among respondents who relied on bore-hole, tap, sachet, or well (closed, potentially un-infested water sources) for domestic use. This value $(30.31 \%)$ as well as the mean infection intensity (31.39 eggs/10 $\mathrm{ml}$ of urine) for this category, is of major concern.

The mean infection intensity was highest (34.29 eggs/ $10 \mathrm{ml}$ of urine) among those who swam and also played in shallow water, followed by those who either played in shallow water or had a history of swimming (32.83 eggs/10 $\mathrm{ml}$ of urine). The lowest mean intensity of infection in respondents who depended on all open water sources (dams, ponds, rivers and streams) was found to be 11 eggs/10 $\mathrm{ml}$ of urine (see Table 4 and Fig. 4).

In the bivariate analysis, the combinations of using dams, ponds, rivers, or streams [COR (95\% CI): 2.09 (1.59-2.76)], dams, ponds, rivers, and streams [COR (95 \% CI): 6.89 (1.38 - 34.49)] and playing in shallow water and swimming [COR (95 \% CI): 2.87(2.03-4.07)] were found to be significantly associated with frequency of infection with urogenital schistosomiasis (see Table 4).

Generally, water contact activities were strongly linked with the transmission of the disease (Chi square test $=29.0312, P<0.0001)$.

Prevalence and intensity of urogenital schistosomiasis in relation to the LGA, infection category, and occupation of respondents' parents

Of the total number of infected respondents, 175 $(88.83 \%)$ fell into the light intensity category, while 22 


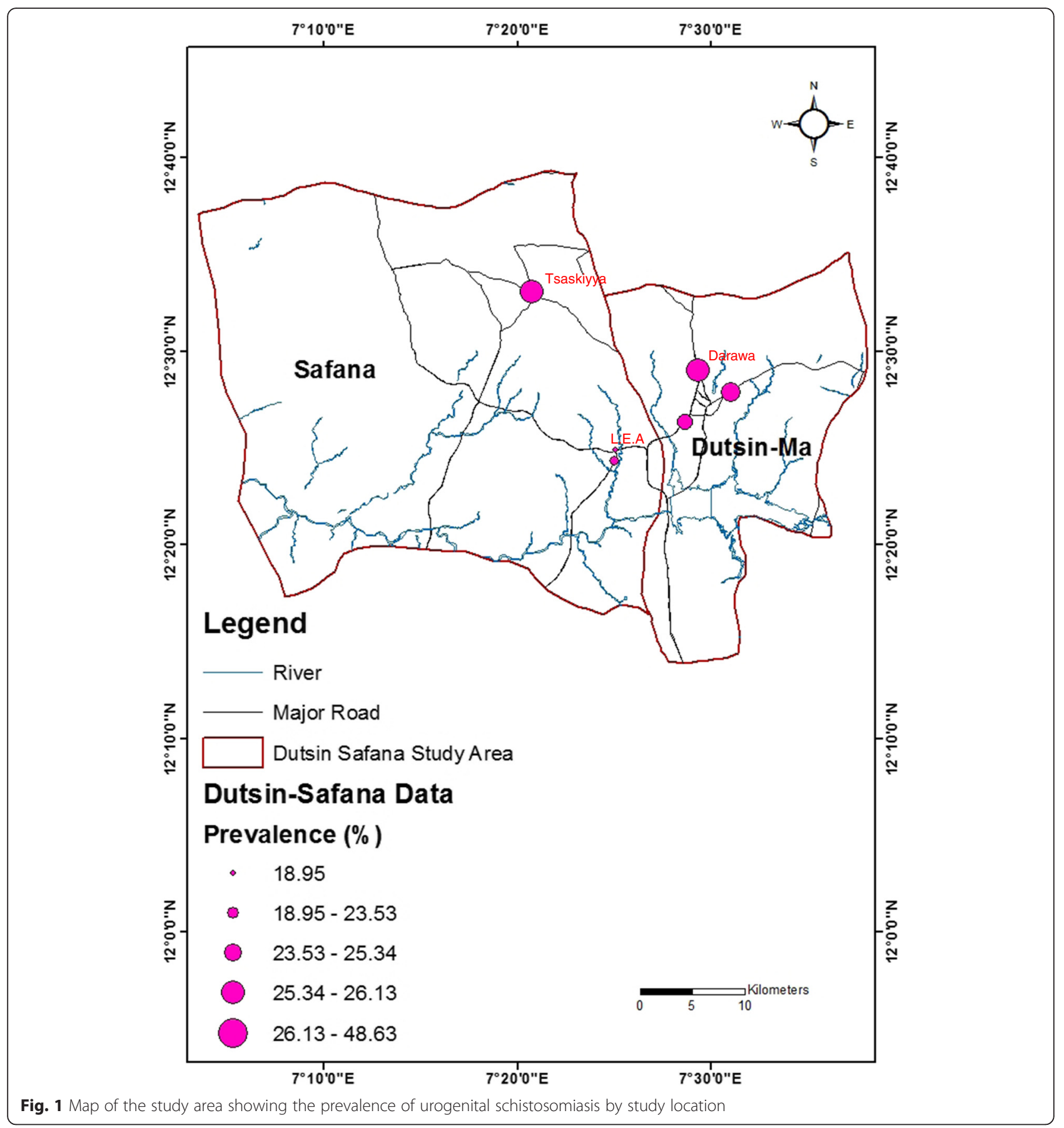

(11.17 \%) belonged to the heavy intensity category. Out of the infected respondents, $59(29.95 \%)$ and 138 (70.05 \%) lived in the Safana and Dutsin-Ma LGAs, respectively. Similarly, of the 5, 933 S. haematobium eggs recovered, 4,792 eggs were recorded in Dutsin-Ma (mean $=34.72$ eggs $/ 10 \mathrm{ml}$ of urine), while 1,141 eggs were recorded in Safana (mean $=19.34$ eggs $/ 10 \mathrm{ml}$ of urine). Invariably, Dutsin-Ma recorded a higher prevalence and mean intensity of urogenital schistosomiasis (see Table 5).
In the father's occupation category, the highest prevalence $(14.57 \%)$ of urogenital schistosomiasis was recorded among children whose fathers did "other browncollar jobs" (mechanics, vulcanizers, cleaners, labourers, etc.) while the highest mean intensity $(37.25$ eggs $/ 10 \mathrm{ml}$ of urine) of infection was identified among children whose fathers were "farmers" (see Table 5 and Fig. 5). Similarly, in the mother's occupation category, children whose mothers did "other brown-collar jobs" had the highest prevalence (18.75\%) of urogenital schistosomiasis 


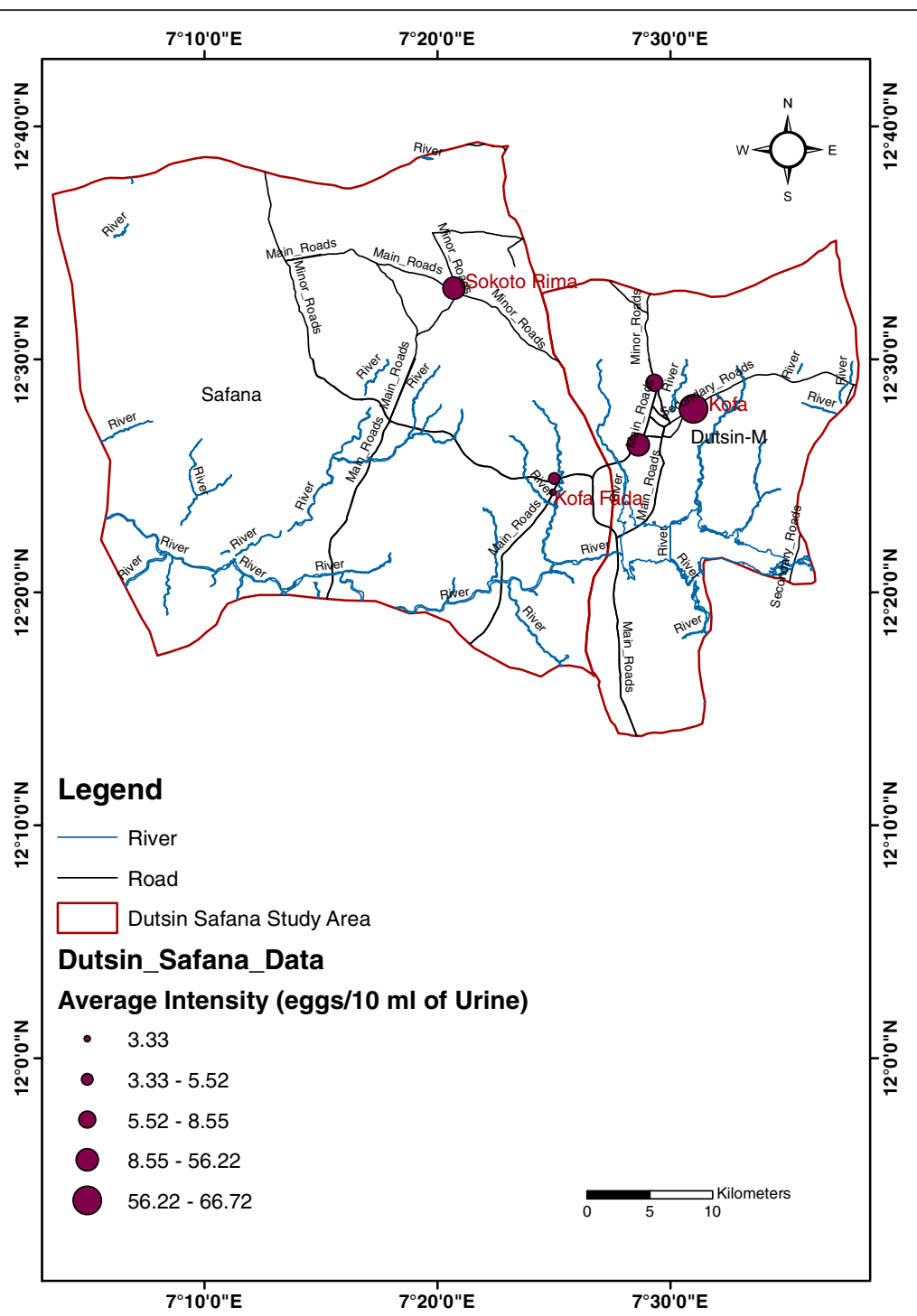

Fig. 2 Map of the study area showing the mean intensity of urogenital schistosomiasis infection by study location

and associated mean egg count (41.73 eggs/10 $\mathrm{ml}$ of urine) [see Table 5 and Fig. 6].

\section{Bivariate and multivariate analyses of factors associated with urogenital schistosomiasis}

In the bivariate analysis, sex (male) [COR (95\% CI): 13.32 (7.64-24.39)], location (Dutsin-Ma) [COR (95\% CI): $1.63(1.27-2.09)]$, and altitude [COR (95 \% CI): 1.57 $(1.12-2.22)]$ were found to be significantly associated with the prevalence of urogenital schistosomiasis. In the father's occupation category, only the variable "other brown-collar jobs" [COR (95 \% CI): 1.73 (1.27-2.36)] was found to be significantly associated with $S$. haematobium infection. The variables "other brown-collar jobs" [COR (95\% CI): 2.48 (1.91-3.27)] and "house wives" [COR (95\% $C I): 1.62(1.15-2.27)]$ as the mother's occupation, were also found to be significantly associated with the disease (see Table 6). In the multivariate logistic regression analysis, only sex $(P<0.0001)$ was found to be statistically associated with the disease.

Boys were six times more likely to be infected with the cercariae of $S$. haematobium compared to girls [AOR (95 \% CI): 6.34 (4.89-8.22)]. Respondents in the DutsinMa LGA were twice [AOR (95\% CI):2.31 (1.76-3.03)] as likely to suffer infection due to $S$. haematobium. Similarly, students whose fathers' occupations belonged to the "other brown-collar jobs" category were about two times [AOR (95\% CI): 1.97 (1.40-2.77)] more likely to be infected than those whose fathers' occupations belonged to the "white collar jobs" category.

Similarly, respondents whose mothers' occupation belonged to the "other brown-collar jobs" category were 
Table 3 Prevalence and intensity of urogenital schistosomiasis in relation to age and sex

\begin{tabular}{cccll}
\hline & N.E & N.I & Prevalence (\%) & $\begin{array}{l}\text { Egg count (Mean) } \\
95 \% \mathrm{Cl}\end{array}$ \\
\hline Sex & & & & \\
Boys & 405 & 183 & 28.37 & $5863[32.21(19.01-45.42)]$ \\
Girls & 240 & 14 & 2.17 & $70[5(-1.21-11.21)]$ \\
$P$ value & & & & $<0.0001$ \\
Age & & & & $760[47.5(-35.63-130.63)]$ \\
$12-14$ & 51 & 16 & 2.48 & $3546[33.77(15.14-52.41)]$ \\
$15-17$ & 385 & 106 & 16.43 & $1562[23.31(11.93-34.69)]$ \\
$18-20$ & 183 & 67 & 10.38 & $62[8.86(0.03-17.69)]$ \\
$21-23$ & 24 & 7 & 1.09 & $3(3)$ \\
$24-26$ & 2 & 1 & 0.16 & 0.0220 \\
$P$ value & & & & $5933[30.27(17.97-42.57)]$ \\
Total & 645 & 197 & $30.54(27.04-34.28)$ &
\end{tabular}

NOTE: Prevalence rate for each determinant factor was calculated by using the number infected as the numerator while the total number of those interviewed in the survey (645) served as the denominator.

N.E Number Examined

N.I Number Inspected

C.I Confidence Interval

about two times [AOR (95 \% CI): 1.89 (1.39-2.56)] more likely to be infected than those whose mothers' occupation belonged to the "white collar jobs" category (see Table 6).

\section{Discussion}

Several studies on urogenital schistosomiasis among preschool children, school-aged children, and adults have been conducted, yet little data exist about urogenital schistosomiasis in senior high school students. Often, findings on this category, where available, have been merged with other groups of school-aged children. This study showed a prevalence of $30.54 \%$ (27.04-34.28 \%) of urogenital schistosomiasis among senior high school students in the study area. Expectedly, due to the focal nature of the infection, this result is different from previous findings of $26.8 \%$ in Ebonyi State, South East Nigeria, $52.8 \%$ at the point -of- care in northeastern Zimbabwe, and $44.3 \%$ in North Central Nigeria [17-19]. The differences observable among these prevalence rates might be linked to ecological factors, cultural practices, and water contact activities unique to our study population. This may require further investigation.

The mean intensity of infection was 30.27(17.97-42.57) eggs $/ 10 \mathrm{ml}$ of urine in this study. Previous records from Anambra State, South East Nigeria (10.1 eggs/ $10 \mathrm{ml}$ of urine), Kaduna State, North West Nigeria (73.93 eggs/ $10 \mathrm{ml}$ of urine) and the Republic of Chad ( $<13.5$ eggs/ $10 \mathrm{ml}$ of urine) further confirm the focal nature of urogenital schistosomiasis [20-22]. These differences might be as a result of seasonal variations, proximity of infested water bodies, natural tendency of subjects towards recreation (swimming and playing in shallow water), and the state of social amenities in both the study area and some states in Nigeria mentioned above.

A higher prevalence rate of urogenital schistosomiasis (28.37 \%) and a higher mean intensity of infection (32.21eggs/ $10 \mathrm{ml}$ of urine) were recorded among males. This conforms to the usual trend recorded previously [23-25] and could be explained by males having more frequent contact with water due to swimming, fishing, molding bricks from clay, and irrigation and construction work.

However, there are contrary reports from Ogun State, Nigeria (Males: $57.1 \%$, Females: $59.2 \%$ ) and Khartoum North, Sudan (Males: $22 \%$, Females: $34 \%$ ) where females suffered a higher prevalence rate of urogenital schistosomiasis $[14,26]$. This might be explained by gender-sensitive cultural or religious beliefs unique to ethnic groups which predispose a particular gender to a higher infection rate in the aforementioned areas. For instance, in the northern part of Nigeria, school-aged males fetch water from open sources for sale in a bid to make ends meet.

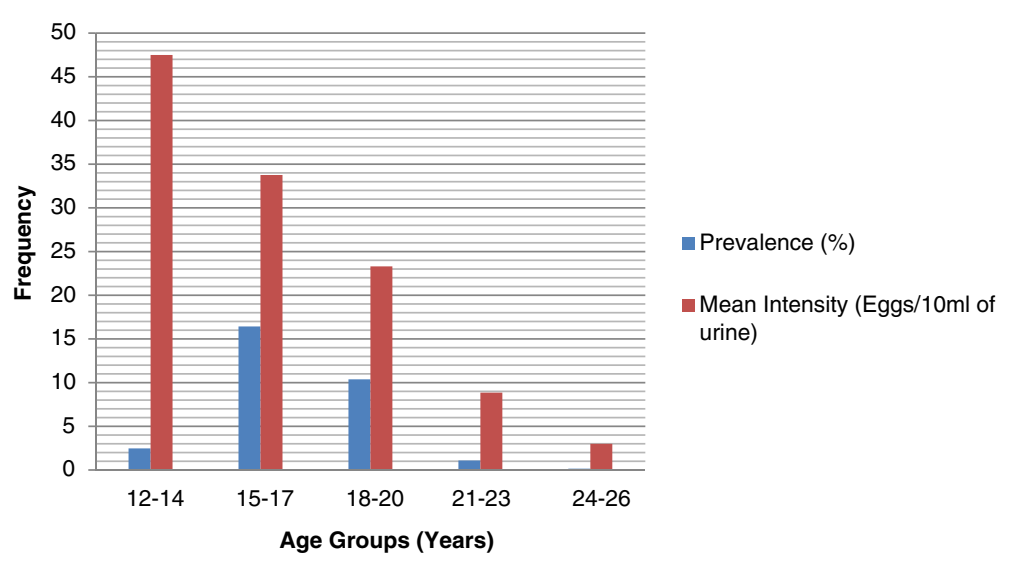

Fig. 3 Age group-related prevalence and intensity of urogenital schistosomiasis in the study LGAs 
Table 4 Frequency and intensity of urogenital schistosomiasis in relation to combined water sources for domestic and recreational uses

\begin{tabular}{|c|c|c|c|c|c|}
\hline Water sources & N.E & N.I & Odds Ratio & ECAM & \\
\hline (Combined) & (\%) & (\%) & $(95 \% C l)$ & $(95 \% C l)$ & $P$ value \\
\hline Dam, Pond, River or Stream & $346(100)$ & $165(47.69)$ & $2.09(1.59-2.76)$ & $29.89(17.45-42.34)$ & $<0.0001$ \\
\hline Dam, Pond, River \& Stream & $8(100)$ & $6(75.00)$ & $6.89(1.38-34.49)$ & $11(-0.67-22.67)$ & 0.0196 \\
\hline Borehole, Tap, Sachet or Well & $617(100)$ & $187(30.31)$ & 1 (Reference) & $31.39(18.52-44.27)$ & - \\
\hline Borehole, Tap, Sachet \& Well & 0 & 0 & 0 & 0 & - \\
\hline Playing in shallow water or swimming & $191(100)$ & $62(32.46)$ & $1.11(0.78-1.57)$ & $32.83(3.46-62.19)$ & 0.6359 \\
\hline Playing in shallow water \& swimming & $171(100)$ & $95(55.56)$ & $2.87(2.03-4.07)$ & $34.29(14.91-53.68)$ & $<0.0001$ \\
\hline
\end{tabular}

ECAM Egg Count Arithmetic Mean

Generally, the results of this survey reflected that the prevalence rate of urogenital schistosomiasis and associated infection intensity reduced sharply as age increases. This is in agreement with previous findings in Nigeria and Sudan $[23,26]$ and is possibly due to the cultural practice of according dignity to older children by exempting them from domestic activities that require contact with unwholesome water sources. Access to knowledge about the epidemiology of urogenital schistosomiasis through Health Science and Biology offered as subjects might also contribute to this. In addition, the older people get, the more possible it is to acquire knowledge about disease prevention and control. Conversely, previous studies from Senegal and Ethiopia have reported increases in prevalence of urogenital schistosomiasis as the age of the respondents increased $[13,27]$, which could possibly be explained by the children in these studies showing an increase in water contact activities as they grow older.

Moreover, the highest prevalence rates in this study were recorded in the age groups of $15-17(16.28 \%)$ and $18-20$ $(10.38 \%)$ years. This implies, on a general note, that these adolescents engage in more water contact activities than the other age groups in this survey. It could be further deduced that they shoulder the responsibility of providing water for their homes. The lowest prevalence rate $(0.16 \%)$ and mean intensity of infection ( 3 eggs/10 ml of urine) was recorded in the $24-26$ age group. However, the highest mean intensity (47 eggs/10 ml of urine) of infection was recorded in the age group 12-14 years, which is suggestive of more contact with streams, rivers, ponds and lakes while swimming and sourcing water for domestic needs.

In agreement with these findings, it was reported that the highest mean intensity of urogenital schistosomiasis was recorded in the age group of 10-14 years in Plateau State, North Central Nigeria and Ebonyi State, South East Nigeria [23, 28].

Other studies carried out in Plateau and Ogun States, Nigeria reported that the highest prevalence rates were observed in the age group of 15-19 years [25, 29]. Findings from Ebonyi State also reported that the age group above 24 years showed the lowest mean intensity of infection with urogenital schistosomiasis [28].

Also noteworthy is the fact that respondents were reliant on multiple sources of water for domestic consumption. Combined recreational activities of swimming and playing in shallow water [COR $(95 \%$ Cl): 2.87 (2.03-4.07)] using dams, ponds, rivers and streams [COR (95 \% CI): 6.89 (1.38-34.49)]; and using dams, ponds, rivers or streams [COR (95\% CI): 2.09 (1.59-2.76)] were significantly associated with urogenital schistosomiasis.

Respondents who relied on dams, ponds, rivers and streams had the highest frequency of infection (75\%), while those who combined swimming with playing in shallow water bodies recorded the second highest

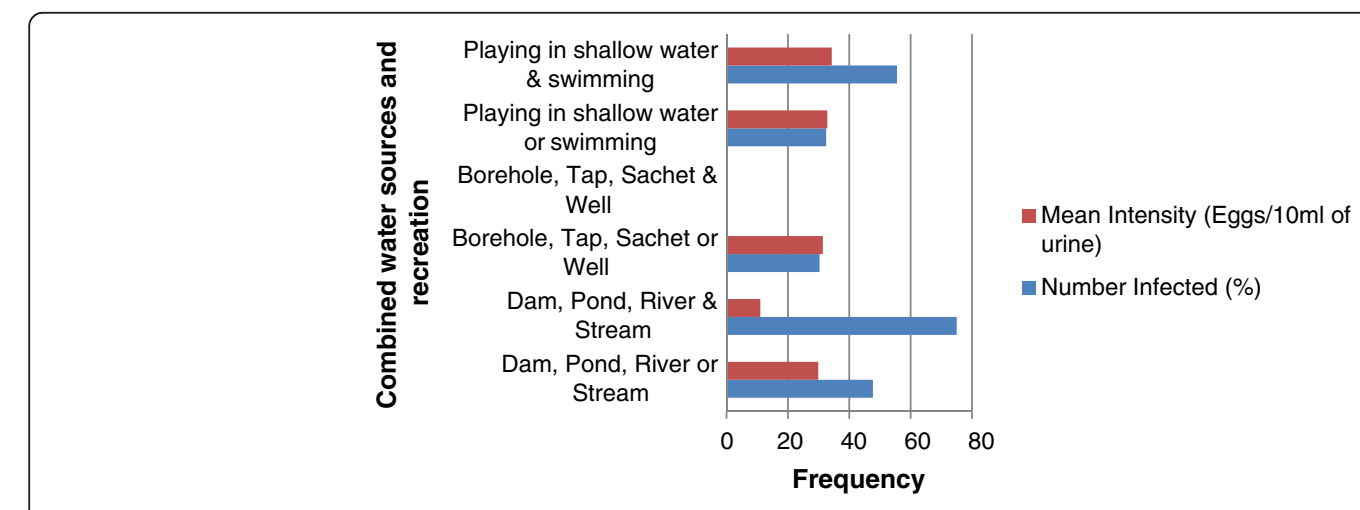

Fig. 4 Water source-related prevalence and intensity of urogenital schistosomiasis in the study LGAs 
Table 5 Prevalence and intensity of urogenital schistosomiasis in relation to LGAs, category of S. haematobium infection and parental occupation of respondents

\begin{tabular}{|c|c|c|c|c|}
\hline & N.E & N.I & Prevalence (\%) & Egg Count [Mean] \\
\hline & & & & $95 \% \mathrm{Cl}$ \\
\hline Safana & 243 & 59 & 9.15 & $1141[19.34(-2.03-40.71)]$ \\
\hline Dutsin-Ma & 402 & 138 & 21.39 & $4792[34.72(19.88-50.08)]$ \\
\hline$P$ value & & & 0.0073 & \\
\hline \multicolumn{5}{|l|}{ Infection category } \\
\hline Light ( $\leq 50$ eggs/10ml) & 175 & 175 & 27.13 & 1456 [8.32(6.82-9.91)] \\
\hline Heavy ( $\geq 50$ eggs/10ml) & 22 & 22 & 3.41 & $4477[203.5(121.14-285.86)]$ \\
\hline \multicolumn{5}{|l|}{ Father } \\
\hline White Collar Jobs & 274 & 71 & 11.01 & 1270 [17.89(0.19-36.09)] \\
\hline Farming Other brown & 113 & 32 & 4.96 & $1192[37.25(0.62-73.89)]$ \\
\hline Collar jobs & 249 & 94 & 14.57 & $3471[36.93(18.41-55.44)]$ \\
\hline Late (Dead) & 6 & 0 & 00.00 & 0 \\
\hline Retiree & 3 & 0 & 00.00 & 0 \\
\hline$P$ value & & & 0.3516 & \\
\hline \multicolumn{5}{|l|}{ Mother } \\
\hline White Collar Jobs & 66 & 12 & 1.86 & 248 [20.67(1.90-39.43] \\
\hline Farming & 1 & 0 & 00.00 & 0 \\
\hline Other Brown Collar Jobs & 338 & 121 & 18.75 & $5007[41.38(22.13-61.32)]$ \\
\hline Late (Dead) & 2 & 1 & 00.16 & $6(6)$ \\
\hline House wifery & 238 & 63 & 9.77 & $672[10.67(4.53-16.81)]$ \\
\hline$P$ value & & & 0.0021 & \\
\hline Total & 645 & 197 & 30.54 & $5933[30.27(17.97-42.57)]$ \\
\hline
\end{tabular}

infection rate $(55.56 \%)$ and the highest mean intensity of infection (34.29 eggs/10 $\mathrm{ml}$ of urine). These are reflections of a high frequency of exposure of the respondents to infested open water bodies. However, a survey conducted in Malawi [30], found that play/bath in an open water body was not found to be associated with urogenital schistosomiasis infection [COR (95 \% CI): 1.21 (0.35-4.10)]. This suggests that interactions among determinant factors play a significant role in the transmission of the disease.

Furthermore, this survey found that the second highest mean intensity of infection (32.83 eggs/10 $\mathrm{ml}$ of urine) was recorded among subjects who either played in shallow water or had a previous history of swimming. A survey carried out in Kaduna State indicated that users

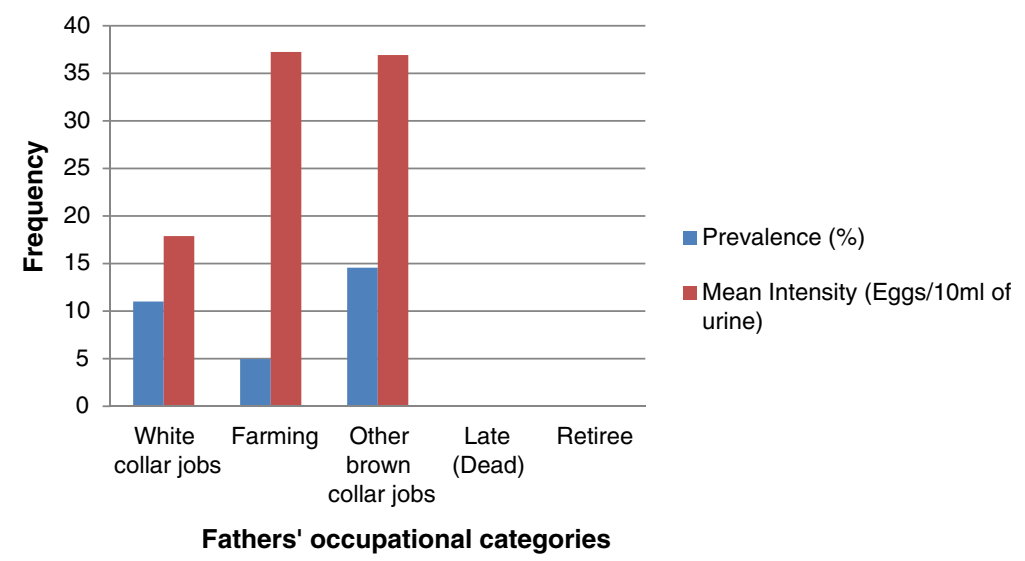

Fig. 5 Father's occupation-related prevalence and intensity of urogenital schistosomiasis in the study LGAs 


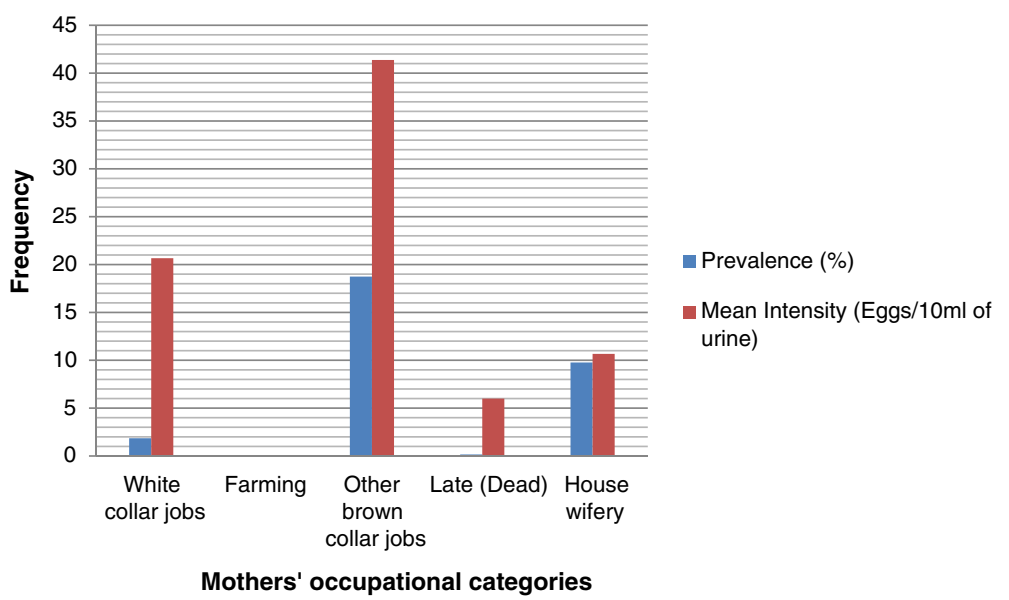

Fig. 6 Mother's occupation-related prevalence and intensity of urogenital schistosomiasis in the study LGAs

of pond water had the highest prevalence rate urogenital schistosomiasis [21], while in Northern Ghana and Blantyre, Malawi, contact with streams, wells, rivers, streams, dams, and springs was found to be associated with $S$. haematobium infection $[30,31]$. It is pertinent to recall that the values of disease prevalence $(30.31 \%)$ and mean intensity of infection (31.39 eggs/10 ml of urine) obtained among users of bore-holes, taps, sachets and wells appear outrageously high, and there are different perspectives on this. One reason could be due to respondents largely utilizing open, infested water sources, although well water, has the highest tendency of being exposed to the environment compared to other closed water sources. On the other hand, it could be hypothesized that the wells in the study area were shallow and either completely uncovered or partially covered, thus enhancing interaction with $S$. haematobium egg-infested dust particles.

In addition, modern waste disposal facilities are limited and the terrain of the study area is dusty and rocky. Consequently, the soil is stony and it is usually very tasking to dig deep while constructing wells in the locality. Surveys conducted in Malawi and Dikwa, Borno State, North East Nigeria [30,32], are not in agreement with these findings.

In this study, location was associated with urogenital schistosomiasis [COR (95 \% $\quad C I): ~ 1.63$ (1.27-2.09)]. Respondents who lived in Dutsin-Ma were twice as likely to be infected [COR (95\% CI): 2.31 (1.76-3.03)] compared to those living in Safana. This is consistent with the knowledge that infection becomes prevalent in areas close to dams and the Dutsin-Ma LGA is home to the Zobe Dam, which provides water for irrigation, fishing, recreational activities, and domestic use. Previous studies from Sudan and Nigeria [10, 19] have reported the role location plays in the prevalence of the disease.
Altitude [COR (95 \% CI): 1.59 (1.14-2.24)] was also found to be associated with infection. Respondents from a higher elevated area had a higher chance of becoming infected with the cercariae of $S$. haematobium probably because such elevations are prone to higher temperatures which favor the hatching of eggs laid by adults into miracidia larvae. Moreover, higher elevated areas easily accumulate water, which in turn harbor the snail intermediate host. Findings in Cross River State, Nigeria, reported a prevalence of $0 \%$ for altitudes above $500 \mathrm{~m}$ [33]. In China, people living at the lake-beach level (with hill as a reference point for other elevations) reportedly had the highest odds of getting infected with $S$. japonicum, a closely related species to $S$. haematobium [34].

In the father's occupation category, "other brown-collar jobs" was associated with urogenital schistosomiasis [COR $(95 \% C I): 1.73(1.19-2.52)$ ], with respondents belonging to this category being about twice [AOR (95\% CI): 1.97 $(1.40-2.77)]$ as likely to be infected compared to those whose fathers jobs belonged to "the white- collar jobs" category. In the mother's occupation category, "other brown-collar jobs" was significantly associated with the disease [COR (95 \% CI): 2.51 (1.29-4.87)], and respondents with mothers in this group are about two times [AOR (95 \% CI):1.89 (1.39-2.56)] as likely to be infected compared to those whose mothers' jobs belonged to the "white-collar jobs" category. The category of "brown-collar jobs" is closely associated with poverty. Parents of such respondents live below USD 4 per day. In addition to this, the network of potable water sources in the study area is very weak [11]. Consequently, people in this job category cannot exclusively rely on wholesome water sources. Studies conducted in Mali and Yemen has shown that level of income is pertinent to the transmission of urogenital schistosomiasis $[35,36]$. 
Table 6 Multivariate analysis of the variables associated with the frequency of urogenital schistosomiasis among respondents

\begin{tabular}{|c|c|c|c|c|c|}
\hline \multirow[t]{2}{*}{ Variables } & \multicolumn{3}{|c|}{ Frequency of Urogenital Schistosomiasis } & \multirow[t]{2}{*}{$\operatorname{COR}(95 \% C l)$} & \multirow[t]{2}{*}{$\mathrm{AOR}(95 \% \mathrm{Cl})$} \\
\hline & Subtotal & Positive (\%) & Negative (\%) & & \\
\hline \multicolumn{6}{|l|}{ Sex } \\
\hline Boys & $405(100)$ & $183(45.19)$ & $222(54.81)$ & $13.32(7.64-24.39)$ & $6.34(4.89-8.22)$ \\
\hline Girls & $240(100)$ & 14(5.83) & $226(94.17)$ & 1 & 1 \\
\hline Chi Square & & & & 109.82 & 43.82 \\
\hline$P$ value & & & & $<0.0001$ & $<0.0001$ \\
\hline \multicolumn{6}{|l|}{ Age } \\
\hline $12-14$ & $51(100)$ & $16(31.37)$ & $35(68.63)$ & $1.20(0.63-2.25)-$ & \\
\hline $15-17$ & $385(100)$ & $106(27.53)$ & $279(72.47)$ & 1 & 1 \\
\hline $18-20$ & $183(100)$ & $67(36.61)$ & $116(63.39)$ & $1.52(1.04-2.21)$ & $1.06(0.68-1.66)$ \\
\hline $21-23$ & $24(100)$ & $7(29.17)$ & $17(70.83)$ & $1.08(0.41-2.64)-$ & \\
\hline $24-26$ & $2(100)$ & $1(50.00)$ & $1(50.00)$ & $2.62(0.07-102.99)-$ & \\
\hline Chi Square & & & & 2.66 & \\
\hline$P$ value & & & & 0.1032 & \\
\hline \multicolumn{6}{|l|}{ Address } \\
\hline Dutsin-Ma & $402(100)$ & $138(34.33)$ & $264(65.67)$ & $1.63(1.27-2.09)$ & $2.31(1.76-3.03)$ \\
\hline Safana & $243(100)$ & $59(24.28)$ & $184(75.72)$ & 1 & 1 \\
\hline Chi Square & & & & 7.19 & 12.89 \\
\hline$P$ value & & & & 0.0073 & 0.0003 \\
\hline \multicolumn{6}{|l|}{ Altitude } \\
\hline $509-529 m$ & $307(100)$ & $78(25.41)$ & $229(74.59)$ & 1 & 1 \\
\hline $530-558 m$ & $338(100)$ & $119(34.91)$ & $219(65.09)$ & $1.59(1.14-2.24)$ & $1.11(0.75-1.66)$ \\
\hline Chi Square & & & & 7.257 & 0.274 \\
\hline$P$-Value & & & & 0.0071 & 0.6008 \\
\hline \multicolumn{6}{|l|}{ Father } \\
\hline White Collar Jobs & $274(100)$ & $71(25.91)$ & $203(74.09)$ & 1 & 1 \\
\hline Farmers & $113(100)$ & $32(28.32)$ & $81(71.68)$ & $1.13(0.69-1.84)$ & - \\
\hline Other Brown Collar Jobs & $249(100)$ & $94(37.75)$ & $155(62.25)$ & $1.73(1.19-2.52)$ & $1.97(1.40-2.77)$ \\
\hline Late (Dead) & $6(100)$ & $0(00.00)$ & $6(100.00)$ & 0 & - \\
\hline Retiree & $3(100)$ & $0(00.00)$ & $3(100.00)$ & 0 & - \\
\hline Chi Square & & & & 0.87 & \\
\hline$P$ value & & & & 0.3516 & \\
\hline \multicolumn{6}{|l|}{ Mother } \\
\hline White Collar Jobs & $66(100)$ & $12(18.18)$ & $54(81.82)$ & 1 & 1 \\
\hline Farmers & $1(100)$ & $0(00.00)$ & $1(100.00)$ & 0 & - \\
\hline Other Brown Collar Jobs & $338(100)$ & $121(35.79)$ & $217(64.21)$ & $2.51(1.29-4.87)$ & $1.89(1.39-2.56)$ \\
\hline Late (Dead) & $2(100)$ & $1(50.00)$ & $1(50.00)$ & $4.50(0.26-77.14)$ & - \\
\hline House Wives & $238(100)$ & $63(26.47)$ & $175(73.53)$ & $1.62(0.81-3.23)$ & - \\
\hline Chi Square & & & & 9.485 & \\
\hline$P$ value & & & & 0.0021 & \\
\hline Grand Total & $645(100)$ & $197(30.54)$ & $448(69.46)$ & & \\
\hline
\end{tabular}




\section{Conclusion}

This study showed that Dutsin-Ma and Safana are moderate-risk LGAs for urogenital schistosomiasis. The association of using a combination of borehole, tap, sachet, or well water and acquiring the disease is noteworthy. To this end, further research that seeks to unravel the relationship between the depth/condition (covered or uncovered) of wells and urogenital schistosomiasis is highly recommended. The strong association between the disease and mother's occupation is of utmost importance and suggests a promising control measure: that is, health education and grassroots mass chemotherapeutic intervention with praziquantel should be directed at mothers. This, like malaria control, could form the basis for the domestic management of schistosomiasis. A Good network of treated pipe-borne water will definitely reduce school children's contact with infested open water sources.

Non-governmental organizations should distribute molluscicides periodically. A good network including treated pipe-borne water, drainage system, and sewage disposal facilities available should be improved upon.

\section{Additional file}

Additional file 1: Multilingual abstracts in the six official working languages of the United Nations. (PDF 804 kb)

\section{Abbreviations}

Cl, confidence interval; LGA, Local Government Area; OR, odds ratio; SD, standard deviation

\section{Acknowledgements}

The authors sincerely acknowledge the support of the director of the Zonal Education Authority, Dutsin-Ma, who was in charge of the high schools in the study LGAs. We also acknowledge the cooperation of all principals as well as the staff of the selected schools. Special thanks go to the amiable respondents for their splendid contribution to this study.

\section{Availability of data and materials}

The data used to arrive at the conclusion of this paper are part of a large data set. Consequently, they are not part of this paper. However, they will be made available on request. Such request should be directed to the corresponding author.

\section{Authors' contributions}

The study was conceived and designed by TEA with UL participating in the field and laboratory work. FOA prepared the maps that showed the prevalence rates and mean intensity of infection in the study locations. Statistical analysis as well as the writing of the paper was carried out by TEA. All authors unanimously approved the final version of the paper.

\section{Authors' information}

TEA and UL: Department of Biological Sciences, Faculty of Science, Federal University, Dutsin-Ma, P.M.B. 5001, Dutsin-Ma, Katsina State, Nigeria, West Africa.

FOA: Department of Remote Sensing and GIS, School of Earth and Mineral Sciences, Federal University of Technology, Akure, Ondo State, Nigeria.

\section{Competing interests}

This study did not receive any external funding. Therefore, the authors declare that they have no competing interests.

\section{Author details}

${ }^{1}$ Department of Biological Sciences, Faculty of Science, Federal University, Dutsin-Ma, P.M.B. 5001, Dutsin-Ma, Katsina State, Nigeria. ${ }^{2}$ Department of Remote Sensing and GIS, School of Earth and Mineral Sciences, Federal University of Technology, Akure, Ondo State, Nigeria.

Received: 3 February 2016 Accepted: 20 June 2016

Published online: 02 August 2016

\section{References}

1. Nour NM. Schistosomiasis: Health Effects on Women. Rev Obstet Gynecol. 2010;3:28-32.

2. World Health Organization. Schistosomiasis, Fact Sheet No 115. 2010 February 2010, . Available at http://www.who.int/mediacentre/factsheets/ fs115/en/. Accessed: 7 Dec 2015.

3. World Health Organization 2010b: Weekly epidemiological record 30 April No.18, 2010, 85, 157-164. Available at http://www.who.int/wer/en/. Accessed: 7 Dec 2015

4. World Health Organization. Schistosomiasis: population requiring preventive chemotherapy and number of people treated in 2010. Wkly Epidemiol Rec. 2012;87:37-44.

5. Centre for Disease Control: The burden of schistosomiasis. 2011. Available at www.cdc.gov/globalhealth/ntd/diseases/schisto_burden.html, Accessed on 9 Oct 2015

6. Hotez PJ, Kamath A. Neglected tropical diseases in Sub-Saharan Africa: review of their prevalence, distribution and disease burden. PLoS Negl Trop Dis. 2009;3, e412.

7. Kabatereine N, Brooker S, Tukahebwa EM, Kazibwe F, Onapa AW. Epidemiology and geography of Schistosoma mansoni in Uganda: implications for planning control. Trop Med Int Health. 2004;9:372-80.

8. King $\mathrm{CH}$, Keating CE, Muruka JF, Ouma JH, Houser H, Siongok TK. Urinary tract morbidity in schistosomiasis haematobia: associations with age and intensity of infection in an endemic area of Coast Province, Kenya. Am J Trop Med Hyg. 1988;39(4):361-8.

9. Leder K and Weller P: Epidemiology; pathogenesis; and clinical features of schistosomiasis Up-To-Date. 2009. Available at http://cursoenarm.net/ UPTODATE/contents/mobipreview.htm. Accessed 23 June 2016.

10. Deribe K, Eldaw A, Hadziabduli S, Kailie E, Omer MD, Mohammed AE, Jamshed T, Mohammed EA, Mergani A, Ali GA, Babikir K, Adem A, Hashim F. High prevalence of urinary schistosomiasis in two communities in South Darfur: implication for interventions. Parasit Vectors. 2011;4:14.

11. National Bureau of Statistics: Annual abstract of statistics, Federal Republic of Nigeria. 2011. Available at: http://www.nigerianstat.gov.ng/report/187. Accessed on 23 June 2016.

12. Abaje BI, Sawa BA, Ati OF. Climate variability and change, impacts and adaptation strategies in Dutsin-Ma Local Government Area of Katsina State, Nigeria. J Geography Geol. 2014;6(2):1916-9779.

13. Senghor B, Diallo A, Sylla SN, Doucouré S, Ndiath MO, Gaayeb L, Djuikwo-Teukeng FF, Bâ CT, Sokhna C. Prevalence and intensity of urinary schistosomiasis among school children in the district of Niakhar, region of Fatick, Senegal. Parasit Vectors. 2014;7:5

14. Ekpo UF, Laja-Deile A, Oluwole AS, Sam-Wobo SO, Mafiana CF. Urinary schistosomiasis among preschool children in a rural community near Abeokuta, Nigeria. Parasit Vectors. 2010;3:58.

15. European Centre for Disease Prevention and Control. Rapid risk assessment: Local transmission of Schistosoma haematobium in Corsica, France. Stockholm: ECDC; 2014.

16. WHO Expert Committee. Prevention and control of schistosomiasis and soil-transmitted helminthiasis: report of a WHO expert committee. World Health Organ Tech Rep Ser. 2002;912:1-57.

17. Uneke C, Oyibo P, Ugwuoru C, Nwanokwai A, lloegbunam R. Urinary schistosomiasis among school -age children in Ebonyi State, Nigeria. Int J Lab Med. 2006;2(1):1-7.

18. Nausch N, Dawson EM, Midzi N, Mduluza T, Mutapi F, Doenhoff MJ. Field evaluation of a new antibody-based diagnostic Schistosoma haematobium and S. mansoni at the point-of-care in northeast Zimbabwe. BMC Infect Dis. 2014;14:165.

19. Okwori AEJ, Sidi M, Ngwai YB, Obiekezie SO, Makut MD, Chollom SC, Okeke IO, Adikwu TI. Prevalence of Schistosomiasis among Primary School Children in Gadabuke District, Toto LGA, North Central Nigeria. Br Microbiol Res J. 2014;4(3):255-61 
20. Ugochukwu DO, Onwuliri COE, Osuala FOU, Dozie INS, Opara FN, Nwenyi UC. Endemicity of schistosomiasis in some parts of Anambra State, Nigeria. J Med Lab Diagn. 2013;4(5):54-61.

21. Kanwai S, Ndams IS, Kogi E, Abdulkadir JS, Gyam ZG, Bechemagbor A. Cofactors influencing prevalence and intensity of Schistosoma haematobium infection in sedentary Fulani settlements of Dumbi, Igabi LGA, kaduna State, Nigeria. Sci World J. 2011;6(2):15-9.

22. Brooker S, Beasley M, Ndinaromtan M, Madjiouroum EM, Baboguel M, Djenguinabe E, Hay SI, Bundy DAP. Use of remote sensing and a geographical information system in a national helminth control programme in Chad. Bull World Health Organ. 2002;80(10):783-9.

23. Dawet A, Benjamin CB, Yakubu DP. Prevalence and intensity of Schistosoma haematobium among residents of Gwong and Kabong in Jos North Local Government Area, Plateau State, Nigeria. Int J Trop Med. 2012;7(2):69-73.

24. Amuta EU, Houmsou RS. Prevalence, intensity of infection and risk factors of urinary schistosomiasis in pre-school and school-age children in Guma Local Government Area, Nigeria. Asian Pac J Trop Med. 2014;34-39.

25. Kabiru M, Muhamed RA, Ikeh El, Aziah I, Julia O, Fabiyi JP. A multivariate analysis on the assessment of risk factors associated with infections and transmission of Schistosoma haematobium in some selected areas of Northwestern Nigeria. J Med Bioengin. 2015;4(1):7-11.

26. Bakhit HA, Shanan S, Saad MB. The prevalence of Schistosoma haematobium among the population of Keryab village, Sharg El Nil, Khartoum North with emphasis on secondary bacterial infection. Sudan Med Lab J. 2011;1:36-46.

27. Geleta S, Alemu A, Getie S, Meconnen Z, Erko B. Prevalence of urinary schistosomiasis and associated risk factors among Abobo Primary School. children in Gambella Regional State, Southwestern Ethiopia: a cross sectional study. Parasit Vectors. 2015;8:215.

28. Obeagu El, Nwosu DC, Nwachukwu PC, Avoaja DA, Ajero CMU, Nwanjo HU, Nnorom RM, Okpara KE, Kanu SN. Index of potential contamination for urinary schistosomiasis in Afikpo North L.G.A., Ebonyi State, Nigeria. Euro J Biomed Pharm Sci. 2015;2(1):439-50.

29. Sam-Wobo SO, Ajayi TO, ljaduola T, Ekpo UF, Adeleke MA, Surakat OA, Mafiana CF. Status of urinary schistosomiasis among primary school children in Abeokuta, Nigeria. Int J Med Med Sci. 2013;5(3):106-9.

30. Kapito-Tembo AP, Mwapasa V, Meshnick SR, Samanyika Y, Banda D, Bowie C, Radke S. Prevalence Distribution and Risk Factors for Schistosoma hematobium Infection among School Children in Blantyre, Malawi. PLoS Negl Trop Dis. 2009;3(1), e361.

31. Anto F, Asoala V, Adjuik M, Anyorigiya T, Oduro A, Akazili J, Akweongo P, Bimi L Hodgson A. Childhood Activities and Schistosomiasis Infection in the Kassena-Nankana District of Northern Ghana. Infect Dis Ther. 2014;2:4.

32. Balla HJ, Babagana I. Dr. Baba S, and Ibrahim H: Incidence of urinary schistosomiasis among out-of-school pupils and almajiris in Dikwa, North Eastern Nigeria. Glob J Med Res -C: Microbiol Pathol. 2015;15(2):8-14.

33. Adie HA, Okon OE, Arong GA, Ekpo UF, Braide El. Environmental factors and distribution of urinary schistosomiasis in Cross River State, Nigeria. Inte J Zool Res. 2014:10(2):42-58.

34. Yang J, Zhao Z, Li Y, Krewski D, Wen SW. A multi-level analysis of risk factors for Schistosoma japonicum infection in China. Int J Infect Dis. 2009:13:e407-12.

35. Dabo A, Diarra AZ, Machault V, Touré O, Niambélé DS, Kanté A, Ongoiba A, Doumbo O. Urban schistosomiasis and associated determinant factors among school children in Bamako, Mali, West Africa. Infect Dis Poverty. 2015:4:4.

36. Sady H, Al-Mekhlafi HM, Mahdy MA, Lim YA, Mahmud R, Surin J. Prevalence and associated factors of schistosomiasis among children in Yemen: implication for an effective control programme. PLoS Negl Trop Dis. 2013;7(8):e2377.

\section{Submit your next manuscript to BioMed Central and we will help you at every step:}

- We accept pre-submission inquiries

- Our selector tool helps you to find the most relevant journal

- We provide round the clock customer support

- Convenient online submission

- Thorough peer review

- Inclusion in PubMed and all major indexing services

- Maximum visibility for your research

Submit your manuscript at www.biomedcentral.com/submit
() BioMed Central 